\title{
Plasmablastic Lymphoma of the Oral Mucosa
}

National Cancer Institute

\section{Source}

National Cancer Institute. Plasmablastic Lymphoma of the Oral Mucosa. NCI Thesaurus.

Code C80290.

A plasmablastic lymphoma arising in the oral cavity, usually associated with HIV infection. 